\title{
Uma mala, um arquivo: escritas ordinárias em cadernos de usos não escolares
}

A suitcase, an archive: ordinary writing in notebooks used outside school settings

Una maleta, un archivo: escrituras ordinarias en cuadernos de usos no escolares

\author{
Vania Grim Thies \\ Universidade Federal de Pelotas (Brasil) \\ http://orcid.org/0000-0002-6169-067X \\ http://lattes.cnpq.br/2559006899606199 \\ vaniagrim@gmail.com
}

\section{Resumo}

A guarda da memória familiar é destinada às mulheres, salvo raras exceções. Os arquivos pessoais, com seus objetos em diferentes suportes, são reveladores de sociabilidades e sensibilidades dos rastros cotidianos. Nesse sentido, o presente artigo tem como objetivo analisar o arquivo pessoal de uma mulher com pouca escolarização, de modo a compreender os registros escritos como suporte de memória. Trata-se de uma pessoa comum que registrou contas, escreveu listas de nomes e sobrenomes, acontecimentos regionais, nacionais e mundiais, além de outras coisas. Foram analisados seis cadernos de usos não escolares que compõem temporalidades distintas entre os anos 1946 a 2012, trazendo os registros de traços do vivido no cotidiano rural por meio da escrita ordinária. A discussão teórica e metodológica está ancorada nos pressupostos da História Cultural e traz contribuições à História da Educação e à História do Tempo Presente por meio dos registros efêmeros.

Palavras-chave: Arquivos pessoais. Escritas ordinárias. História da Educação. 


\begin{abstract}
Except in rare cases, women are responsible for keeping family memories. Personal archives and its objects in different media reveal how social and sensible are everyday traces. In that context, this paper seeks to analyze the personal archives of an unschooled woman to understand how written records support those memories. The subject of this research is an ordinary woman who recorded accounts, lists of names and surnames, regional, national, and world events, and other. We analyzed six notebooks used outside school settings that correspond to different time periods between 1946 and 2012. They reveal traces of rural, everyday life through ordinary writing. Theory and methodology for this paper are based on Cultural History premises. It contributes to History of Education and to Contemporary History by analyzing ephemeral records.
\end{abstract}

Keywords: Personal archives. Ordinary writing. History of Education.

\title{
Resumen
}

La guardia de la memoria familiar es destinada a las mujeres, salvo raras excepciones. Los archivos personales, con sus objetos en diferentes soportes, revelan sociabilidades y sensibilidades de los rastros cotidianos. En este sentido, el presente artículo tiene el objetivo de analizar el archivo personal de una mujer de escasa escolaridad para comprender los registros escritos como apoyo a la memoria. Se trata de una persona común que registró cuentas, escribió listados de nombres y apellidos, hechos regionales, nacionales y mundiales, además de otras cosas. Han sido analizados seis cuadernos de usos no escolares que componen temporalidades distintas entre los años 1946 y 2012, trayendo los registros de rasgos de lo vivido en el cotidiano rural por medio de la escritura ordinaria. La discusión teórica y metodológica está basada en los presupuestos de la Historia Cultural y trae contribuciones a la Historia de la Educación y a la Historia del Tiempo Presente a través de los registros efímeros.

Palabras clave: Archivos personales. Escrituras ordinarias. Historia de la Educación. 


\section{Introdução}

Começo da nossa vidal! Com essa pequena frase afirmo que adentrar memórias privadas não é tarefa fácil, especialmente quando se trata deum arquivo familiar permeado por laços de afetividades. Trabalhar com arquivos pessoais é, sobretudo, trabalhar com a memória do privado (PERROT, 2005). É refletir sobre as redes de relações e sobre a história de determinados sujeitos que guardam tais documentos. A produção deste texto é inspirada em um arquivo pessoal familiar cuidadosamente armazenado pelas mãos de uma avó que entregou à neta, autora deste artigo, uma mala com papéis e objetos, em sua maioria, já guardados há mais de uma geração.

Assim, o presente artigo tem como objetivo analisar o arquivo pessoal de uma mulher com pouca escolarização, tendo como foco seis cadernos de usos não escolares, de modo a compreender seus registros escritos como suporte de memória. Trata-se de uma pessoa comum que registrou contas, escreveu listas de nomes e sobrenomes, listas de músicas, datas de aniversário, os acontecimentos locais, regionais, nacionais e mundiais, além de outras coisas.

$\mathrm{O}$ arquivo condensado e organizado em uma mala conta não só com documentos da pessoa que registrou nos cadernos analisados neste artigo, mas também com notas fiscais enroladas e amarradas com fitinhas coloridas, documentos dispersos de outros integrantes da família e, alguns objetos de uso pessoal (peças de vestimentas, óculos, moedas, etc.). A maioria desses materiais, pelas datas e nomes indicados pertenceu a uma geração familiar anterior.

Segundo Perrot (2007, p. 30), “organizar arquivos, conservá-los, guardá-los, tudo isso impõe uma certa relação consigo mesma, com sua própria vida, com sua memória". Com essa afirmação, a pesquisadora francesa alerta que a destruição e a autodestruição são mais frequentes do que a guarda dos próprios materiais, à exemplo dos diários femininos muitas vezes destinados ao fogo antes da divisão de uma vida conjugal. Perrot (2005, p. 37), ao dedicar-se à história das mulheres no século XIX, afirma que "mais do que ao escrito proibido, é ao mundo calado e permitido das coisas que as mulheres confiam sua memória". Se o escrito é proibido, é muitas vezes nos objetos colecionados e guardados que as mulheres confiam sua memória, os seus "mil nadas".

É também sobre esses aspectos que, ao receber um arquivo materializado em uma mala, pude perceber uma história silenciada desta avó, mulher comum, agricultora que frequentou por poucos anos a escola. Ao arrumar seus pertences, destinou para a próxima geração feminina suas próprias memórias na forma de documentos escritos e a partir de objetos pessoais afetivos. Dessa forma, chega-se ao que restou "das mulheres do passado nas mulheres de hoje (e que não é pouco)" (PERROT, 2005, p.39): uma mala ávida por ser aberta, "expondo quinquilharias e relíquias da memória familiar e grupal de seu tempo [...] torna possível, para o historiador, conhecer outros detalhes de acontecimentos sociais, culturais e políticos de uma época" (CUNHA, 2019, p.102).

Conservar a memória dos homens também foi uma tarefa destinada à mulher que escreveu nos cadernos que ora problematiza-se. Neste caso, homens sem visibilidade na vida política ou social. Na mala também foi possível encontrar documentos dos homens da família que prestaram serviço militar entre os anos de 1942 a 1945. Este fato corrobora para a afirmação de que é às mulheres que a guarda da memória familiar é confiada.

Os registros encontrados nos cadernos não somente revelam a reflexão e a sensibilidade consigo mesma, mas também as relações de sociabilidade e as notícias ao redor do mundo. Os cadernos mesclam os escritos cotidianos revelados no gênero diário e nas contabilidades domésticas, inscrevendo fragmentos da história local, regional, nacional e internacional. São datados em um tempo histórico, escritos no espaço

\footnotetext{
${ }^{1}$ Registro realizado no ano de 2012, um dos últimos registros produzidos, presente em um dos cadernos analisados.
} 
doméstico, trazendo a ordenação do cotidiano sem perder a relação com o contexto social mais amplo. Dessa forma, as fontes contribuem com a historiografia da educação na intersecção do presente e da longa duração (DOSSE, 2012).

Nomeadas de escritas ordinárias por Daniel Fabre (1993), referem-se às escritas sem qualidade científica realizadas por pessoas comuns e que se opõem aos escritos prestigiados, elaborados com a vontade de fazer uma obra para ser impressa. Esse conceito indica que mesmo as pessoas que não estão vinculadas ao uso da escrita nas suas atividades profissionais utilizam-se dela e produzem uma variedade de registros em diferentes suportes. São as escritas das pessoas comuns (GÓMEZ, 2003), geralmente com escassa alfabetização, com passagem breve pela escola, e que usam o escrito por outras razões pessoais, deixando traços do cotidiano, que inseridos em um contexto social e histórico "permitem aos historiadores rastrearem muitas das maneiras de viver e de pensar determinada época, dadas a ver, no tempo presente" (CUNHA, 2013, p. 252).

Documentos escritos, fragmentados, muitas vezes em listas; acontecimentos locais, algumas notícias regionais e outras mundiais. Além disso, o controle de vendas e parcas anotações sobre reformas da casa ou reparos em galpões da propriedade rural. Uma escrita autobiográfica realizada por uma mulher de origem rural, moradora de um município ao sul do Rio Grande do Sul (Brasil) e que frequentou por poucos anos a escola primária, na década de 1930 do século XX. Escritas com erros de grafia e trocas de letras que indicam escassos conhecimentos de ortografia, produzidas por esta mulher de descendência pomerana ${ }^{2}$ que, por isso, fazia o uso de mais de uma língua segundo o contexto em que estivesse inserida, utilizando-se oralmente da língua pomerana em casa, enquanto na escola aprendia em língua alemã. Pelos registros apresentados nos seus cadernos escolares ${ }^{3}$, datados de 1938, com escritas em alemão e em português, foi possível identificar as influências da nacionalização do ensino naquele período com a proibição do uso da língua alemã. A língua portuguesa também era utilizada junto às situações formais fora do contexto doméstico ${ }^{4}$.

Os cadernos analisados apontam seus usos com a presença de fatos do cotidiano desde o ano de 1946 até 2012. Escritas que se entrelaçam entre o controle de contas da casa e da propriedade rural, a escrita de si, a escrita que foi atenta às datas de acontecimentos familiares e, a escrita diária de acontecimentos, de curiosidades, provavelmente ouvida pelos meios de comunicação (o rádio e a televisão). O que estes traços escritos podem indicar? Quais as contribuições que este tempo tão presente traz à História da Educação?

\section{Da vida privada aos acontecimentos internacionais: registros em fragmentos efêmeros}

Os seis cadernos foram utilizados para registrar os fatos mais efêmeros do cotidiano, desde listas de nomes à cronologia da vida com suas datas mais importantes. Para isso, não foram organizados em ordem cronológica ano após ano, ou dia após dia. Datam de diferentes temporalidades correspondentes aos anos de 1946 a 2012. Em um único caderno, há registros de vários anos e todos foram realizados com caneta esferográfica (azul, preta, vermelha e, em menor número de vezes, em verde). A partir desse dado é possível inferir que houve a revisita

\footnotetext{
${ }^{2}$ Os pomeranos eram provenientes do território da Pomerânia, região localizada no litoral do Mar Báltico. Eram descendentes de eslavos e wendes, que trabalhavam principalmente na agricultura e na pesca (RÖLKE, 1996). São considerados um grupo étnico com características próprias e peculiares, mantendo língua e costumes diferenciados de outros grupos étnicos alemães (WEIDUSCHADT; TAMBARA, 2014)

${ }^{3} \mathrm{O}$ centro de memória e pesquisa Hisales (História da Alfabetização, Leitura, Escrita e dos Livros EscolaresFaE/UFPEL) salvaguarda 2 cadernos escolares (um de 1937 e outro de 1938) e a cartilha utilizada na alfabetização da autora dos materiais. Os cadernos escolares apresentam escritas em alemão e em português, demonstrando o período da nacionalização do ensino materializado nos materiais escolares. Para saber mais sobre o centro de memória e pesquisa Hisales ver em www.ufpel.edu.br/fae/hisales/.

${ }^{4}$ Para saber mais sobre a utilização da língua pomerana, ver em BAHIA (2011).
} 
aos cadernos em diferentes momentos, possivelmente para o acréscimo de alguma informação e rememoração de tantas outras. Assim, ainda que a análise tenha procurado seguir uma certa temporalidade cronológica, nem sempre correspondeu de fato à cronologia das produções escritas tendo em vista que um caderno foi usado e revisitado muitas vezes.

Outro fator suscitado na análise dos cadernos, as fontes historiográficas deste estudo, é o fato já evidenciado por Hébrard (2000), sobre o espaço gráfico que desliza de uma função à outra.

Todos ligados entre si, eles constituem um continuum homogêneo que obedece tanto às lógicas do tempo (memorial, diário) quanto às da razão (livro grande) ou ainda às da divisão do trabalho (livros auxiliares). Esse continuum oferece muito precocemente, através da escrita, as múltiplas formas de acesso à tradução da complexidade do mundo. Permite pôr em prática técnicas, sutis de mudança de ponto de vista, para uma mesma operação, oferecem ao olhar visões diferentes da mesma realidade (HÉBRARD, 2000, p. 45).

As palavras do autor auxiliam nas reflexões sobre a funcionalidade, a razão e as diferentes temporalidades presentes em cada um dos seis cadernos que serão descritos na sequência. Afirmo com isso, que cada caderno foi utilizado sem a preocupação em escrever de forma linear, ano após ano. Foram escritos e informações foram sendo acrescentadas à medida do necessário, do que o cotidiano rural impunha, ou à medida que a autora dos registros sentia necessidade de voltar a escrever adicionando informações em tal caderno. Para uma melhor compreensão, os cadernos serão descritos, um a um, procurando destacar as informações relevantes à análise. Como pesquisadora, procurei estabelecer uma ordem de descrição seguindo os anos de registros, mesmo que, conforme já dito, as datas não obedecessem a uma linearidade rígida.

O primeiro caderno ${ }^{5}$ a ser descrito não apresenta datas em nenhuma de suas quinze folhas, apenas o registro do ano de 1947 na capa, juntamente com o nome da autora das escritas e da localidade. No conjunto dos seis, esse é considerado o primeiro caderno, pois, tendo em vista o conjunto de documentos, foi possível verificar que em 1946 a autora dos registros casou-se.

Registrar seria uma maneira de arquivar a memória do privado, tal como "sobre a família e o cotidiano, que se pergunte às mulheres!" (PERROT, 1989, p. 17). O desejo de registrar os traços do vivido desde o início da vida conjugal, numa relação de guarda da memória, parecenos que começa com o desejo de tornar o presente e o passado visíveis também no futuro, para serem novamente lidos e preservado, tal como uma continuidade feminina da memória.

Junto às folhas desse primeiro caderno, há papéis soltos, tais como, notas de compras, listas, anúncios de rádio, anotações referentes à um relógio (data da compra, primeira reforma e segunda reforma): "Este relógio foi comprado ano 1934. Teve 20 anos parado des Novembro 1971. Começo trabalhar 21 de abril 1991. Foi na reforma 19 Outubro 2007. Custo 40.00 real $^{6 "}$ ".

Nos manuscritos nas folhas internas há dias e meses com nomes de pessoas e a localidade/município proveniente. Pela forma de registro (dia, mês, sem ano de referência), infere-se que são datas de aniversário. Nas 3 folhas finais, há listas com o nome de músicas e as indicações do ritmo de cada uma (valsa, rancheira, polca), numa espécie de coletânea de

\footnotetext{
${ }^{5}$ A capa expressa uma representação de país com a máxima "Brasil: Ame-o com energia". A frase curta é uma analogia à alimentos apresentados na contracapa do caderno: farinho de milho (Maizena), açúcar e leite.

${ }^{6}$ As escritas foram mantidas como estavam inscritas no papel e representando uma escassa escolarização com marcas de oralidade. Transcrição: Este relógio foi comprado no ano de 1934. Esteve 20 anos parado [sem uso] desde novembro de 1971. Começou a trabalhar [funcionar] em 21 de abril de 1991. Foi para reforma em 19 de outubro de 2007. Custou 40,00 reais.
} 
ritmos. Na margem do caderno há a indicação do ritmo "valsa" com a letra "V" e do ritmo "polca" com a inscrição "pol”, conforme é possível verificar na figura 1.

Figura 1-Listas de músicas (s/d)

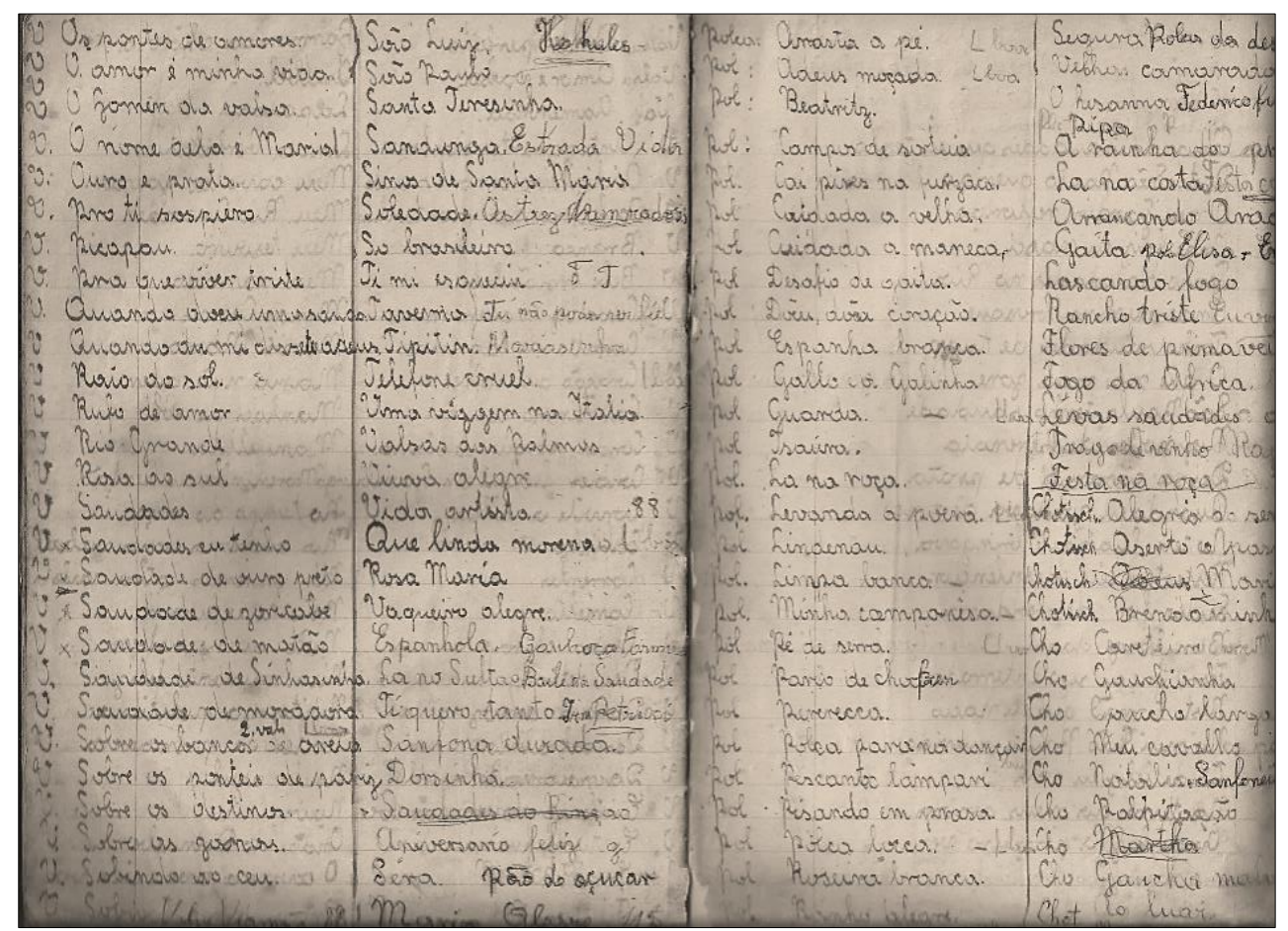

Fonte: Arquivo pessoal

Pela coloração da caneta esferográfica utilizada nos manuscritos, é possível verificar que a revisita ao caderno aconteceu ao longo de diferentes anos, com a inserção de novos nomes na listagem de nomes e datas de aniversário, bem como mais nomes de músicas e ritmos. A escrita no formato de listas é algo recorrente nesse e nos demais cadernos em análise. De acordo com Eco (2010), à medida que uma lista caracteriza uma série, ela confere ordem a um conjunto que sem isso seria desordenado. Escrever na forma de listas também está associado à escassa apropriação da escrita, sendo mais fácil para o que se propõe: arquivar nomes, músicas, aniversários, e demais aspectos do cotidiano.

O uso da folha do caderno é algo que chama atenção, é dividida em duas partes e há o aproveitamento total dela, tal como se não houvessem margens ou linhas. Seria essa uma necessidade de aproveitar todos os espaços para a escrita por receio de não ter outro caderno para continuar a escrever? Ou é possível pensar o suporte e o seu uso não escolar, utilizado para a escrita pessoal, permitindo que a folha fosse utilizada sem preocupações com regras, mas sim "centrada na sensibilidade em relação ao tempo que passa e nos esforços do escritor para dele construir uma representação e uma memória” (HEBRÁRD, 2000, p.30) em diferentes fases de sua vida. Diante de tantas sensibilidades cotidianas inscritas nos cadernos, não há como não indagar: qual representação e qual memória a escrita quer preservar?

Há várias informações que só são possíveis de serem compreendidas no conjunto de registros dos 6 cadernos. Citarei o exemplo de um desenho em formato de planta baixa da construção de uma casa encontrado em um pedaço de papel em meio às folhas do primeiro caderno. Nesse desenho, produzido à lápis, consta uma inscrição à caneta com a data de junho de 1962. Essa informação só foi possível de ser apreendida junto à análise do sexto caderno escrito, no qual há uma listagem dos principais acontecimentos da vida da autora (uma espécie de resumo dos fatos acontecidos) com a informação de datas. Em uma delas 
está registrado: 1962 - Este comsemos a casa 13 de junho, fico proto 13-12-19627. Aquele pequeno papel, na intencionalidade de uma planta baixa de construção, foi o projeto da casa da família. É provável que a inscrição da data à caneta tenha sido colocada muitos anos após a produção do desenho (planta baixa).

Nesse sentido, é importante verificar o arquivo pessoal na sua totalidade, realizando cruzamento das informações para dar a ver determinadas relações no conjunto das fontes que foram arquivadas, pois quem arquiva o faz com um propósito: que alguém, no futuro, desperte os papéis envelhecidos para serem lidos e trazidos para serem problematizados no presente.

O segundo caderno é o que pode ser caracterizado como um caderno de contas, pois apresenta contabilidades da propriedade rural da mesma forma que um livro de razão. Tal como afirma Hébrard (2000, p. 38/39), o "livre de raison é um livro no qual um bom administrador ou negociante escreve tudo o que recebe e gasta para prestar contas e explicar a si mesmo a razão de todos os negócios". Sem a capa e com muitas folhas em branco, o que parece guiar os registros são as safras ${ }^{8}$ sazonais/anuais de produtos cultivados pela família desde o ano de 1953a 2003, ou seja, trata de cinquenta anos do registro de produtos que foram vendidos, com a quantidade vendida ou colhida, preços, quilos de cada produto e, ainda, para quem foram vendidos.

A organização das contas no caderno é uma explicação para si de contas domésticas. Para cada anotação sobre a safra há mais uma página ou várias folhas em branco, como se outras informações ao longo dos anos ainda tivessem que ser acrescentadas com o passar do tempo. Além do registro das safras, também há o registro de gastos com reformas de galpões e as compras de móveis, animais e outras coisas vinculadas com o trabalho rural, tais como ferramentas, sementes, etc. O caderno não pertence à uma pessoa do mundo dos negócios, mas sim busca um controle da própria vida, ou seja, a escrita "com conexão direta com seus usos cotidianos" (GÓMEZ, 2012, p.69).

Em meio aos registros das contas entre as safras de cebolas, batatas, alho, pêssego, flores e verduras, há também a escrita sobre uma viagem ao estado o Paraná intitulada dia 27 de abril 1971! Um passeio S. Helena Paraná. A escrita de duas páginas apresenta o roteiro percorrido com o ônibus por cidades principais e o tempo de viagem de ida e de retorno, bem como os passeios realizados na cidade visitada, em uma espécie de diário da viagem. Um breve relato para cada dia contemplando a data de início, dia 27 de abril de 1971 até o dia 12 de maio do mesmo ano, dia de retorno, finalizando o relato com. Toda viagem custo $350 \mathrm{cr}$. Fim! $!^{9}$ Novamente busco em Hébrard (2000) as inspirações para compreender essas ordens da vida dispersas nos fragmentos escritos de um caderno de contas. Um misto de contabilidade com relato de atividades de lazer pondo ordem ao vivido:

Prestar contas de suas despesas ou de sua vida são atos próximos e que progressivamente se confundem. O espaço gráfico do registro, em partida dobrada, revela-se um lugar onde as ordens escritas oferecem múltiplas possibilidades para pôr em ordem os atos dispersos da existência (HÉBRARD, 2000, p. 39).

Entre diferentes registros, o arquivo vai revelando aspectos diversos da vida com diferentes facetas, passando por diferentes momentos, desde uma viagem realizada, o valor de uma reforma no galpão ou a venda de dúzias de ovos, os diferentes "atos dispersos da existência" (HÉBRARD, 2000) nesse cotidiano do contexto rural que a escrita põe em ordem demarcando uma forma de deixar rastros revelados pelas escritas ordinárias.

\footnotetext{
${ }^{7}$ Transcrição: 1962 - Este [ano] começamos a casa em 13 de junho, ficou pronta em 13-12-1962.

${ }^{8} \mathrm{O}$ termo é o que aparece no próprio caderno para nominar cada cultivo nos diferentes anos.

${ }^{9}$ Transcrição: Toda viagem custou 350 cruzeiros. Fim!
} 
O terceiro caderno apresenta capa com a denominação "Companheiro", referindo-se à sua coleção de produção. Na contracapa está a bandeira do Brasil, indicando a extensão territorial e a população estimada. Apresenta 52 páginas numeradas e as escritas ocupam as capas e folhas, sem espaçamento entre as linhas, com aproveitamento também das margens, ou seja, não há espaços em branco, todos são ocupados pelos manuscritos. Há registros desde o ano de 1996 até 1999, com indicações dos dias e do mês escrito, na maioria, de forma abreviada, na margem do caderno. $\mathrm{O}$ ano de referência está no alto da página. A figura 2 é um exemplo dessa forma de organização das escritas no caderno.

Figura 2:Terceiro caderno (1996)

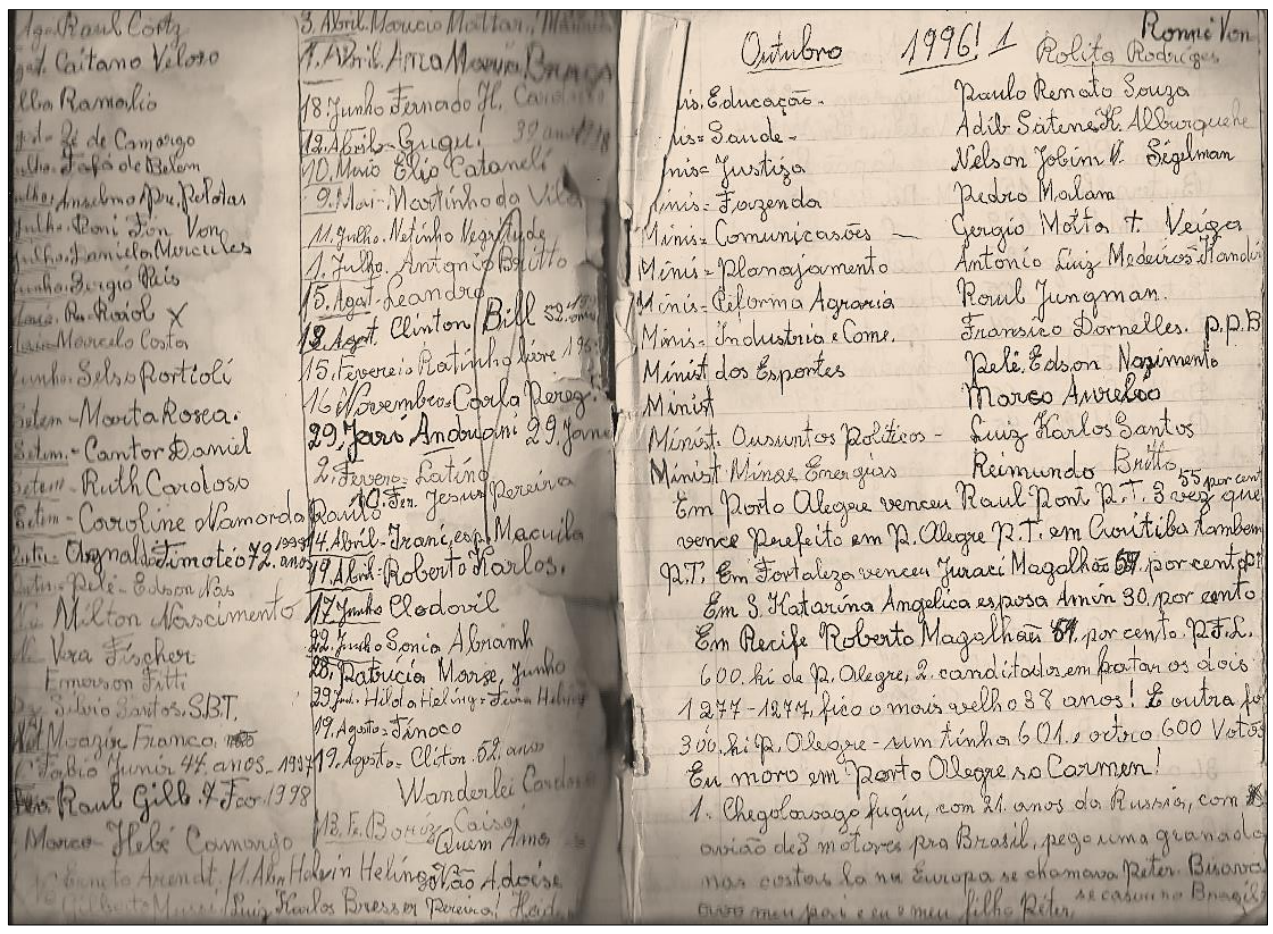

Fonte: Arquivo pessoal

As listas aparecem novamente, desta vez com nomes de pessoas de pessoas influentes nos meios de comunicação, tais como os ministros do governo federal (educação, saúde, justiça, fazenda, comunicação, etc.), cantores brasileiros (Milton Nascimento, Fafá de Belém, Martinho da Vila, etc.) entre outros. Novamente recorro à Umberto Eco (2010), que corrobora com essa discussão afirmando que: "a técnica da lista não pretende colocar em dúvida nenhuma ordem do mundo, pretende, aliás, reconfigurar que o universo da abundância e dos consumos à disposição de todos representa o único modelo de sociedade organizada" (ECO, 2010, p. 353). As escritas são representativas de nomes ouvidos provavelmente nos meios de comunicação que, de forma organizada, vão compondo inscrições junto às datas (dia e mês) como uma maneira de dispor as informações em abundância.

O terceiro caderno descrito aqui é um gênero diário, no entanto, diferentemente da escrita íntima, as escritas nele apresentam acontecimentos locais (eleições municipais), regionais, nacionais e internacionais. Cito mais alguns exemplos além dos já nomeados nas primeiras folhas, tais como: datas de aniversários, acidentes aéreos, morte da princesa Diana, a morte do cantor brasileiro Renato Russo, terremoto na Itália, temporal na Índia, acontecimento nas minas de carvão na Rússia. Esses fatos que misturam os registros dos grandes e dos pequenos acontecimentos "contribuem para a compreensão do passado recente da nossa sociedade e estimulam reflexões sobre a conexão passado-presente" (CUNHA, 2013, p. 259). 
Além disso, algumas informações ou espécies de curiosidades, versos prontos, anúncio de um concurso de paródias, anotações de músicas, nomes de cantores, de novelas e outros programas de televisão, também estão presentes nos registros. Nas folhas finais constam nomes dos jogadores da seleção brasileira de futebol, bem como os nomes de jogadores da seleção da Alemanha, da Dinamarca e da Holanda de 1998, ano que a copa do mundo de futebol foi realizada no país francês.

Dessa forma é possível verificar que temas como política, economia, clima, agricultura, esportes e vida artística estão presentes nas escritas diárias, lado a lado. Alguns exemplos selecionados merecem ser dados a ver:

[Outubro 1996] Em Porto Alegre venceu Raul Pont PT. 55 por cento. 3 vez que vence prefeito em P. Alegre PT em Curitiba também (...). ${ }^{10}$

30. Ago. Morreu princesa Diana em Pariz com 36 anos! Em 1981 casos e Charles, deixa 2 filhos, 1 irmão, 2 irmã nasceu 1 Julho 1961. Os Willian 15 anos Harri 13 anos $^{11}$ (30 de agosto de 1997).

12 Marco - Forte chuva e temporal hoje no Rio de Janeiro (12 de Março de 1998).

21 de Julho Nelson Mandela 80 anos Sul Africano visita Brasil (21 de julho de 1998).

Anotações sobre início ou final de novelas, bem como o nome de uma marca de creme para o rosto, nomes de ministros nacionais e suas respectivas cadeiras ocupadas nos ministérios, também estão presentes. Diante de tantas variáveis e assuntos misturados, há muitas perguntas que precisam ser realizadas durante a leitura do material empírico: qual a seleção realizada por quem escreveu? Por que temas tão diversos aparecem conjuntamente registrados? De onde vêm essas informações? A necessidade de apreender informações sobre os mais diferentes aspectos da vida é algo bastante presente no registro do caderno diário.

Não arquivamos nossas vidas de qualquer maneira, nas palavras de Artières (1998). Segundo ele, "fazemos um acordo com a realidade, manipulamos a existência: omitimos, rasuramos, riscamos, sublinhamos, damos destaques a certas passagens" (ARTIÈRES, 1998, p. 11). Há uma preocupação em dispor a vida pessoal sem descuidar da vida social e daquilo que está circulando como informações importantes ao redor do mundo ou da localidade mais próxima.

Nesse sentido, as informações registradas parecem dispersas, mas acabam compondo a vida pessoal com as reflexões contidas nelas, de acordo com as seleções realizadas para a escrita. Traços da vida pessoal que são registrados em cadernos ao lado de fato locais, regionais, nacionais e internacionais aparecem com detalhes de datas e números nestes cadernos.

Ao compor o organograma dos documentos, busquei e observei nas datas algumas pistas para a compreender como as escritas eram tão pontuais em relação às datas e demais informações que envolviam números. A busca em outros documentos da mala, tais como notas fiscais e comprovantes de pagamento, serviu para complementar tais informações. A compra do primeiro rádio para ser usado com baterias, em 1963, a chegada da luz elétrica na propriedade rural da família, em 1994, e a possibilidade dos entrecruzamentos desses com os demais dados escritos nos cadernos levou-me à reflexão de que os detalhes eram ouvidos e observados juntos aos meios de comunicação para então serem registrados nos cadernos.

\footnotetext{
${ }^{10}$ [Outubro 1996] Em Porto Alegre venceu Raul Pont do partido PT com 55 por cento dos votos. 3 vezes que vence um prefeito do partido do PT em P. Alegre, em Curitiba também.

11 30. Ago [Agosto]. Morreu a princesa Diana em Paris com 36 anos! Em 1981 casou com Charles, deixa 2 filhos, 1 irmão, 2 irmãs, nasceu em 1 Julho 1961. Os filhos Willian 15 anos e Harry $13 \operatorname{anos}^{11}$ (30 de agosto de 1997).
} 
Além disso, minha memória de mulher na condição de neta da autora dos registros nos cadernos também foi reacendida ao rememorar que no móvel onde ficava localizado o rádio e também o aparelho televisor, estava sempre ao alcance um caderno e uma caneta.

O quarto caderno apresenta apenas a capa frontal. De modo semelhante aos registros do caderno anterior, é também, um diário de acontecimentos locais, regionais, nacionais e internacionais com as inscrições do dia e do mês de forma abreviada na margem e uma breve escrita sobre a data. A referência ao ano consta na parte superior da página. As folhas desse caderno foram numeradas até o número 85. Dessas, 62 foram escritas e as de 80 a 85 foram arrancadas.

Os registros compreendem o ano de 1999 (desde o mês de agosto) ao ano de 2012. Neste último, há escritas muito breves, apenas com nomes de pessoas e somente em alguns meses do ano. Nos escassos manuscritos de 2012, é possível verificar que a caligrafia se diferencia das anotações anteriores e que as letras aparecem tremidas, indicando que a escrita já não era regular e diária.

Entre os parcos registros, destaco duas anotações que estão nesta ordem no caderno: a morte do arquiteto brasileiro Oscar Niemayer (5 de dezembro de 2012) e anotações referentes às eleições do município de Morro Redondo (7 de outubro de 2012), pequena cidade do Rio Grande do Sul onde a autora dos registros residia naquele período. A referência às eleições municipais traz o nome dos candidatos a prefeito com o respectivo montante de votação e o nome dos vereadores eleitos, bem como a quantidade de votos de cada um.

Os dois registros, um com reconhecimento internacional (Oscar Niemayer) e outro de reconhecimento local (eleições municipais), nos remetem à noção de "glocal" que Chartier (2009), aponta como "os processos pelos quais são apropriadas as referências partilhadas, os modelos impostos, os textos e os bens que circulam mundialmente, para fazer sentido em um tempo e em um lugar concretos" (CHARTIER, 2009, p. 57).Cabe, assim, aos historiadores da educação algumas perguntas sobre esses documentos: como uma senhora, de origem rural que frequentou por poucos anos a escola, traz em seus registros os acontecimentos locais, regionais, nacionais e internacionais? E, ainda, por que conservou os cadernos de usos não escolares em um arquivo privado até que sua idade garantiu a possibilidade de escrita?

O quinto caderno apresenta registros com datas dos anos 2005 até 2012. Há folhas em brancos no início e no final, como se houvessem muitas coisas a serem escritas. As folhas e o verso da capa foram divididos em duas partes para a escrita. Os manuscritos apresentam listas com datas mensais e nomes completos em certa descontinuidade. $O$ destaque parece não ser a exatidão na sequência das datas, ou no preenchimento de linha após linha, mas sim, a intenção de deixar registrados fatos vivenciados.

As folhas avulsas encontradas junto a esse caderno trazem informações do grupo da terceira idade do qual a autora participava, anúncios de reuniões e atividades sociais do grupo, tais como os bailes mensais e mensagem em relação aos idosos. No conjunto das escritas em confronto com a leitura das folhas avulsas foi possível verificar que tais listas indicavam as datas e locais de realizações (nome o salão) dos bailes com o nome das bandas que os animavam, e, das amizades de baile, com quem a autora dos registros dançou.

É possível verificar que há certa relação entre o registro das informações em listas e a divisão das folhas em duas partes. Escrever sob a forma de listas parece ser uma maneira mais fácil de organizar as informações, tal como o temor de não conseguir dizer tudo (ECO, 2010), mas inscrever as informações consideradas mais importantes, apresentando-os fatos de maneira mais sucinta. A ausência na continuidade da escolarização seria um indicativo do motivo de deixar os registros da vida traçados em forma de listas? Talvez a resposta não seja possível pelo limite das fontes utilizadas, mas é um dos pontos que causa curiosidade porque todos os cadernos apresentam listas com conteúdos variados.

A análise do sexto e último caderno, remete aos registros realizados entre os anos de 2007 a 2012 e, em comparação ao primeiro caderno, encontram-se novas listas com músicas e ritmos (mais valsas, mais rancheiras, mais polcas, etc.). Tal como no primeiro caderno, neste 
último voltam a aparecer as listas com nomes de novelas, listas de nomes repetidos e sobrenomes diferentes, listas com marcas de erva mate e com nomes de farmácias.

Além disso, há um resumo de sua vida em breves datas já com a caligrafia denunciando dedos trêmulos para a escrita. No topo da página há uma descrição “Começo da nossa vida! ” Esse registro segue com breves inscrições indicando o ano e uma pequena frase que sintetiza o conteúdo. O início da vida conjugal em 19 de outubro de 1946, a compra da propriedade rural para o início do trabalho como agricultores em 1947, o nascimento dos filhos gêmeos na casa da família no ano de 1950, cirurgia realizada em 1986, datas variadas de compras de móveis para a casa, datas de acontecimentos ligados à vida rural da família, tais como compra de cavalos e finalização da atividade de venda de leite para a cooperativa... Ainda é possível destacar a compra de uma Bíblia "nova”, em 2009 e, para encerrar, a compra de um pisca-pisca de natal em dezembro de 2012.

Em seu texto intitulado "O guarda-memória", Philippe Lejeune (1997, p. 116) interroga-se "quantas páginas é preciso para alguém contar a sua vida' - Toda a sua vida'. Mas uma vida pode ser tomada no atacado ou no varejo. Pode ser contada do começo ou do meio". Os registros problematizados neste último caderno analisado revelam o varejo, tal como a expressão de Lejune (1997), com pequenas doses daquilo que fez mais sentido para deixar registrado: muitas coisas sem serem escritas por esquecimento, outras tantas intencionalmente sem o registro. A escrita revelou uma breve síntese dos acontecimentos de sessenta e seis anos e que foram sintetizados em duas folhas do sexto caderno. Ressalto que este período não é ainda, a totalidade vivida pois, atualmente (no ano de 2020) a autora das escritas encontra-se com 94 anos, ou seja, muitas coisas não foram ditas!

\section{Considerações finais}

Uma vida resumida em seis cadernos! Uma história que pode ser contada, refletida e rememorada durante vários anos entre o passado e a história recente. Para finalizar o texto, penso nas palavras de Koselleck (2014) “quanto de passado habita no nosso presente?". De acordo com o questionamento, pensaria ainda em mais um acréscimo ao indagar: quanto de futuro temos no nosso presente? O que projetamos, ou à nós é projetado, após receber um arquivo familiar com escritas na materialidade de seis cadernos? E, quanto as histórias registradas nos cadernos poderão contribuir para problematizar o futuro? Qual a relevância de estudar as escritas de uma mulher comum, agricultora, inscritas em suportes e gêneros nem sempre fáceis de nomear? Ao finalizar o artigo, muitos questionamentos ainda permanecem, mais questões e menos certezas.

A provável resposta é seguir perpetuando uma memória familiar feminina via cadernos de usos não escolares com os traços do cotidiano rural, do contexto regional, nacional e mundial, conforme problematizado ao longo dessa escrita. Tarefa para a continuidade das pesquisas com os arquivos pessoais e familiares para os historiadores interessados nos traços, nos registros da ordem da vida cotidiana e nos efêmeros papéis sem qualidade científica.

As escritas nos cadernos de usos não escolares revelam outras formas de existir, de guardar para si e para as próximas gerações femininas as memórias familiares, porque "é ao mundo mudo e permitido das coisas que as mulheres confiam sua memória" (PERROT, 1989, p.13). Escritas em listas, nomes, acontecimentos locais, nacionais e mundiais trazem as múltiplas facetas do cotidiano por meio da escrita ordinária, contribuindo, também, para pensarmos o passado recente nos processos historiográficos da Educação.

\section{Referências}

ARTIÈRES, Philippe. Arquivar a própria vida. Estudos Históricos, Rio de Janeiro, v.11, n. 21, p. 9-34,1998. 
BAHIA, Joana. O tiro da Bruxa: identidade, magia e religião na imigração alemã. Rio de Janeiro: Garamond, 2011.

CUNHA, Maria Teresa Santos. (Des)arquivar: arquivos pessoais e ego-documentos no tempo presente. 1 ed. São Paulo: Florianópolis: Rafael Copetti Editor, 2019.

CUNHA, Maria Teresa Santos. Territórios abertos para a História. In: PINSKY, Carla Bassanezi, DE LUCA, Tânia Regina (Org.). O historiador e suas fontes. São Paulo: Contexto, p. 252-279, 2013.

CHARTIER. Roger. A história ou a leitura do tempo. Belo Horizonte: Autêntica Editora, 2009.

DOSSE, François. História do tempo presente e historiografia. Tempo e Argumento. Florianópolis, v.4, n.1, p.5-22, jan/jun. 2012. DOI: https://doi.org/10.5965/2175180304012012005.

ECO, Umberto. A vertigem das listas. Trad. Eliana Aguiar. Rio de Janeiro: Record, 2010.

FABRE, Daniel. Introduction. In: FABRE, Daniel (org.) Écritures ordinaires, Paris: Bibliothèque Publique D'Information (Centre Georges Pompidou), 1993.

HÉBRARD, Jean. Por uma bibliografia material das escrituras ordinárias: a escrita pessoal e seus suportes. In: MIGNOT, Ana Chrystina Venâncio, BASTOS, Maria Helena Camara, CUNHA, Maria Teresa Santos (Org.). Refúgios do eu: educação, história, escrita autobiográfica. Florianópolis: Mulheres, p. 29-61, 2000.

GÓMEZ, Antonio Castillo. Das mãos ao arquivo. A propósito das escritas das pessoas comuns. Percursos, Florianópolis, v.4, n.1, p. 223-250, jul. 2003.

GÓMEZ, Antonio Castillo. Educação e cultura escrita: a propósito dos cadernos e escritos escolares. Educação, Porto Alegre, v. 35, n. 1, p. 66-72, jan./abr. 2012.

KOSELLECK, Reinhard. O conceito de História. Belo Horizonte: Autêntica, 2014.

LEJEUNE, Philippe. O guarda-memória’. Estudos Históricos, v. 10, n. 19, p. 111-120, 1997.

PERROT, Michelle. Práticas da memória feminina. Revista Brasileira de História. São Paulo, v. 9, n. 18, p. 09-18, Ago/Set 1989.

PERROT, Michelle. As mulheres ou os silêncios da história. Bauru, SP: EDUSC, 2005.

PERROT, Michelle. Minha história das mulheres. São Paulo: Contexto, 2007.

RÖLKE, Helmar Reinhard. Descobrindo raízes, Aspectos Geográficos, Históricos e Culturais da Pomerânia. Vitória: UFES. Secretaria de Produção e Difusão Cultural, 1996.

WEIDUSCHADT, Patrícia; TAMBARA, Elomar; Cultura escolar através da memória dos pomeranos na cidade de Pelotas, RS (1920-1930). Cadernos de História da Educação, v.13, n.2, p.687-704, 2014. 